\title{
Efficacy of Fenugreek-based bionanocomposite on renal dysfunction and endogenous intoxication in high-calorie diet-induced obesity rat model-comparative study
}

\author{
Victoria V. Konopelniuk ${ }^{1}$ - Ievgenii I. Goloborodko ${ }^{1}$ - Tetyana V. Ishchuk ${ }^{1}$ • \\ Tetyana B. Synelnyk ${ }^{1}$ • Ludmila I. Ostapchenko ${ }^{1}$ - Mykola Ya. Spivak ${ }^{2}$. \\ Rostyslav V. Bubnov ${ }^{2,3}$
}

Received: 21 February 2017 / Accepted: 16 May 2017 /Published online: 16 June 2017

(C) European Association for Predictive, Preventive and Personalised Medicine (EPMA) 2017

\begin{abstract}
Background Worldwide obesity spread is a global health problem and needs to be further studied. Co-morbidities of obesity include insulin resistance, diabetes mellitus type 2 , and dyslipidemia, which are the most frequent contributing factors for metabolic syndrome (MetS), as well as nonalcoholic fatty liver disease and chronic kidney disease. The aim was to study renal function and endogenous intoxication panel on high-calorie diet-induced obesity rat model and perform comparative study of the treatment efficacy of Fenugreek-based bionanocomposite vs antiobesogenic drugs (Orlistat).

Materials We included 60 male rats and equally divided them to 6 groups of 10 animals in each group: the experimental groups were firstly assigned as controls and high caloric diet (HCD)-fed groups, and each group further was subdivided to remain untreated, Fenugreek bionanocomposite (BNC)-treated, and Orlistat-treated. Normal control rats (groups 1, 2, 3) were fed by a standard chow, while the others (groups 4, 5, 6) were fed with HCD ad libitum during 98 days. From days 77
\end{abstract}

to 98 , groups 2 and 5 were treated with $\mathrm{BNC}$ based on Fenugreek (150 mg/kg body weight, orally) and groups 3 and 6 were treated with antiobesogenic drug Orlistat (10 mg/kg body weight, orally). Food and water consumptions were measured daily and body weights were measured once a week. On day 99, blood was collected; the creatinine, urea, and uric acid were estimated in serum according to the standard protocols. Levels of low and middle molecules (MMs) were measured; the quantity of oligopeptides was estimated by Bradford method. We performed the liver and kidney ultrasonography in rats.

Results We revealed an increase in the levels of endogenous intoxication syndrome markers (MM and oligopeptides) in all animals with experimental obesity. Ultrasound data showed injury of the liver and kidneys in obese rats. We observed significant decreasing of MM levels after Orlistat treatment vs controls $(p<0.05)$. However, this effect was more pronounced in Fenugreek BNC-treated group vs both Orlistattreated and controls $(p<0.05)$. Orlistat treatment evoked rising of serum creatinine and oligopeptides in control animals

Mykola Ya. Spivak

n.spivak@ukr.net

1 Educational and Scientific Centre "Institute of Biology", Taras Shevchenko National University of Kyiv, Volodymyrska Str., 64/13, Kyiv 01601, Ukraine

2 Zabolotny Institute of Microbiology and Virology, National Academy of Sciences of Ukraine, Zabolotny Str., 154, Kyiv 03143, Ukraine

synelnykt@gmail.com

Ludmila I. Ostapchenko

decanat_bf@univ.kiev.ua
Clinical Hospital "Pheophania" of State Affairs Department, Zabolotny Str., 21, Kyiv 03143, Ukraine 
and failed to normalize these markers in experimental group. Fenugreek-based BNC treatment did not evoke signs of kidney failure and changes in the studied indices in control group. We noticed normalization levels of uric acid and urea in the blood under the use of BNC and Orlistat.

Conclusion High-calorie diet-induced obesity evokes endogenous intoxication syndrome and kidney dysfunction in rats. Application of Orlistat- and Fenugreek-based BNC decreases MM content to the normal level. Orlistat induces increasing levels of oligopeptides in both groups, likely due to adverse side effects on renal function and its pro-oxidant activity.

Keywords Predictive $\cdot$ Preventive $\cdot$ Personalized medicine Obesity $\cdot$ Fenugreek $\cdot$ Bionanocomposite $\cdot$ Renal function . Metabolic syndrome $\cdot$ Obesity $\cdot$ Chronic kidney disease . Endogenous intoxication · Middle molecules · Orlistat . Prebiotic $\cdot$ Animal model $\cdot$ Personalized diet

\section{Overview}

\section{Predictive, preventive, and personalized management of renal dysfunction in obesity}

Worldwide obesity spread became a global health problem and still needs to be studied. Obesity co-morbidities include insulin resistance, diabetes mellitus type 2, and dyslipidemia, which are the most frequent contributing factors for the inception of metabolic syndrome (MetS), as well as non-alcoholic fatty liver disease (NAFLD) that includes steatosis, steatohepatitis, and liver fibrosis and increase the risk of developing chronic kidney disease (CKD) [1, 2].

Endogenous intoxication syndrome (EIS) has several nonspecific displays in organism in pathological conditions with inflammatory effects and metabolome changes. Biological fluids of organism in pathological processes have high contents of lipid and carbohydrate metabolites and when altered demonstrate toxic effects on the liver, kidneys, and brain cells $[3,4]$. Most of these toxins belong to the middle mass molecules (middle weight molecules, middle molecules, MMs).

The middle molecule hypothesis was suggested decades ago by Babb et al. [4] and has been rediscovered recently in personalized medicine via developing unbiased proteomic, genomic, and metabonomic techniques [5]. Middle molecules [4-6] are the heterogeneous group of different chemical substances with molecular weight 500-5000 Da, represented mostly by serum proteins, degradation products oligopeptides, and carbohydrates or lipid (including phospholipids) derivatives. Accumulation of MMs is associated with a number of diseases like pericarditis, heart failure, psychic disturbances, anemia, lung, and brain edema, and may cause neurological complications like polyneuropathy in patients with chronic kidney failure. Oligopeptide MMs can demonstrate vascular-, cardio-, and neuro-toxicity and immunosuppressive properties; alter transport of amino acids, mitochondria respiratory, DNA synthesis, glycolysis and gluconeogenesis, hemoglobin synthesis and erythropoiesis, and anticoagulation processes; they can change activity of some enzymes, hemo- and lymphodynamic; and have cytoprotective effects [4-6]. MM level is a sufficiently precise marker of metabolic intoxication, and yet, the knowledge of the nature of middle molecules is not complete, the evidence showing that a benefit for MM removal has been growing; MM plays crucial role in preservation of residual renal function (RRF), one of the basic therapeutic goals of nephrology and hemodialysis practice.

Obesity is hardly treated and needs multiple therapeutic strategies. They can include restricting caloric intake and increasing physical activity, blocking nutrient absorption in the intestine, modulation of fat metabolism, regulation of intracellular signaling in adipose tissue, and control of the satiety centre. However, various medications that have been used to minimize obesity over the years are now withdrawn due to their serious adverse effects.

Orlistat ( $N$-formyl-L-leucine [2S-[2alpha ( $\left.\mathrm{R}^{*}\right)$, 3beta]]1-[(3-hexyl-4-oxo-2-oxetanyl)methyl]dodecyl ester) is a highly effective antiobesity drug, the saturated derivate of original natural inhibitor of pancreatic lipase lipstatin isolated from Streptomyces toxytricini. It also inhibits the thioesterase domain of fat acid synthase besides [7]. Use of Orlistat was reported to achieve a short-term loss of weight in combination with a hypocaloric diet and changes in lifestyle in obese adolescents, yet typically associated with mild-moderate gastrointestinal adverse effects [8]. Thus, the long-term Orlistat treatment can cause steatorrhea, and result significant reduction of the fat-soluble compounds absorption, including fatsoluble vitamins, primarily $\mathrm{A}$ and $\mathrm{E}$, which are the important components of antioxidant defense.

There is a need to find new substances and new strategies for the effective treatment and prevention of obesity and its comorbidities [9]. The components of natural plant products are widely used as the active components of drugs or as dietary supplements [10].

Trigonella foenum-graecum, or Fenugreek, is an annual plant native to India and North Africa; but now, widely cultivated almost all over the world is this plant, which has been used in herbal medicine for a long time around the world, its leaves and seeds, which are commonly used as leafy vegetables and condiments, and as a traditional herbal medicine as Ayurveda treatments of a variety of conditions and is a part traditional diets (rice preparation) [10-14]. Drugs based on Fenugreek showed hypolipidemic and hypoglycemic effects, have antioxidant properties and hepatoprotective and 
antibacterial effects, stimulating ability of gastric secretion and lactation, and inhibition of tumor growth [10]. Fenugreek-based drugs can reduce body weight and fat mass by stimulating intestinal motility and inhibiting the reabsorption of carbohydrates and fatty acids [11]. Recently, a metabonomics approach was proved to be a novel powerful tool to evaluate the therapeutic mechanisms of herb extracts; in particular, this elucidated that Fenugreek is a potential therapeutic agent via multiple therapeutic mechanisms for the treatment of diabetes [12].

Despite the large number of scientific papers devoted to studying Fenugreek [10, 11, 13, 14], we still lack the definitive views on the use of this plant for the treatment and prevention of obesity, which generally determines the relevance of research under this specific problem.

Thus, here we hypothesize the following:

- High caloric diet-induced obesity elicits renal dysfunction and endogenous intoxication development.

- The use Fenugreek-based drug is effective for the prevention and treatment complications of obesity superior vs existing antiobesogenic drug (Orlistat).

According to our hypothesis, we designed the study on the obesity rat model to perform comparative assessment of treatment efficacy of Fenugreek-based drug and Orlistat using the specific markers of EIS and renal dysfunction [4-6] including levels of oligopeptides, MM, and unspecific biochemical markers of kidney functions: creatinine (creatine phosphate metabolite), urea, and urate (the final products of protein and purine metabolism, respectively) [15].

The aim was to study renal function and endogenous intoxication panel on high-calorie diet-induced obesity rat model and perform comparative study the treatment efficacy of plant (Fenugreek)-based bionanocomposite (BNC) vs antiobesogenic drugs (Orlistat) and to overview up-to-date evidence on using Fenugreek for the prevention and treatment of obesity and renal complications.

\section{Methods}

Research was conducted in compliance with the standards of the Convention on Bioethics of the Council of Europe's "Europe Convention for the Protection of Vertebrate Animals" used for experimental and other scientific purposes (1997), and with other international agreements and national legislation in this field. Animals were kept in a vivarium that was accredited in accordance with the "standard rules on ordering, equipment and maintenance of experimental biological clinics (vivarium)." Instruments used in research were under metrological control. No human subjects have been involved to the study.

\section{Fenugreek-based bionanocomposite preparation}

To maximize the effect of using biologically active substances, $T$. foenum-graecum seeds were transferred to highly dispersed state by immobilization on the surface nanosilex that allowed obtaining bionanocomposite. Mechanical activation of mixture of nanosilex and powdered seeds of T. foenumgraecum was carried out in ball mills. Fumed silica Fine Asyl300 ( $\mathrm{SBET}=340 \mathrm{~m}^{2} / \mathrm{g}$, Kalush, Ukraine) was used. It consists of spherical particles with a diameter of 9-10 nm, which are on the surface silanol groups $\equiv \mathrm{Si}-\mathrm{OH}$ and adsorbed water molecules. The concentration of free silanol groups $(\alpha \mathrm{OH})$ for the selected sample was $0.8 \mathrm{mmol} / \mathrm{g}$.

\section{Animals, housing conditions, and diet}

We included 60 male rats and divided them to 6 groups of 10 animals in each group: the experimental groups were firstly assigned as controls and high caloric diet (HCD)-fed groups, and each group further was subdivided to remain untreated, Fenugreek BNC-treated, and Orlistat-treated.

The animals of each experimental group were individually housed in polypropylene cages in an environmentally controlled clean air room, with a temperature of $22 \pm 3{ }^{\circ} \mathrm{C}$, a $12 \mathrm{~h}$ light $/ 12 \mathrm{~h}$ dark cycle, and a relative humidity of $60 \pm 5 \%$.

Normal control rats (groups 1 -controls remain untreated, 2-controls Fenugreek BNC-treated, and 3-controls Orlistat-treated) were fed by a standard chow, while the others (groups 4- $\mathrm{HCD}$ remain untreated, 5- $\mathrm{HCD}$ Fenugreek BNC-treated, and 6-HCD Orlistat-treated) were fed with HCD ad libitum during 98 days of the experimental period [16]. From days 77 to 98 , groups 2 and 5 were treated with bionanocomposite based on TFG (150 mg/kg body weight, orally) while groups 3 and 6 were treated with Orlistat (10 mg/kg body weight, orally) [17].

Food and water consumption were measured daily at the same time (09:00 to 10:00 h) and body weights were determined once a week.

\section{Collecting serum}

On the 99th day, blood samples were collected at the same time in animals of all groups from the retroorbital plexus of overnight fasted rats under light ether anesthesia and serum was separated by centrifugation at $3000 \mathrm{rpm}$ for $15 \mathrm{~min}$. The serum samples were stored at $-80{ }^{\circ} \mathrm{C}$ until analysis. Body length was measured; body mass index (BMI) (the ratio of body weight $(\mathrm{g})$ of rats to the square of the body length $\left(\mathrm{cm}^{2}\right)$ ) and Lee obesity index (the ratio of 1/4 of cube root of body weight $(\mathrm{g})$ to body nose-to-anus length $(\mathrm{cm}))$ were calculated. 
Table 1 Body weight, body mass index, and Lee index of experimental animals

\begin{tabular}{lllllll}
\hline Parameter & $\begin{array}{l}\text { Controls remain } \\
\text { untreated }\end{array}$ & $\begin{array}{l}\text { HCD remain } \\
\text { untreated }\end{array}$ & $\begin{array}{l}\text { Controls Fenugreek } \\
\text { BNC-treated }\end{array}$ & $\begin{array}{l}\text { HCD Fenugreek } \\
\text { BNC-treated }\end{array}$ & $\begin{array}{l}\text { Controls } \\
\text { Orlistat-treated }\end{array}$ & $\begin{array}{l}\text { HCD } \\
\text { Orlistat-treated }\end{array}$ \\
\hline Body weight $(\mathrm{g})$ & $342 \pm 10.351$ & $430 \pm 11.096^{*}$ & $285 \pm 17.067^{*}$ & $391 \pm 10.906^{* \#}$ & $269 \pm 12.749^{*}$ & $362 \pm 14.090^{* \#}$ \\
Body mass index $\left(\mathrm{g} / \mathrm{cm}^{2}\right)$ & $0.58 \pm 0.032$ & $0.73 \pm 0.012^{*}$ & $0.52 \pm 0.053$ & $0.66 \pm 0.037^{* \#}$ & $0.45 \pm 0.023^{*}$ & $0.69 \pm 0.052$ \\
Body length $(\mathrm{cm})$ & $24.2 \pm 0.981$ & $24.3 \pm 0.805$ & $23.4 \pm 1.093$ & $24.3 \pm 0.992$ & $24.4 \pm 1.101$ & $22.9 \pm 0.926$ \\
Lee index & $0.28 \pm 0.01$ & $0.31 \pm 0.01^{*}$ & $0.28 \pm 0.02$ & $0.3 \pm 0.01$ & $0.26 \pm 0.02$ & $0.31 \pm 0.02$ \\
\hline
\end{tabular}

Data are presented as the $\mathrm{M} \pm \mathrm{SD}$; asterisks $(*) p<0.05$ compared with control value, number signs $(\#) p<0.05$ compared with $\mathrm{HCD}$

\section{Serum biochemistry parameters}

The creatinine, urea, and uric acid were measured using biochemical analyzer Microlab 300 (Elitech, France) and commercial kits from Elitech diagnostic (France) according to the standard protocols provided by manufacturers.

Level of low and medium mass molecules was measured by Gabrielyan's method with modifications [16]. One milliliter of serum and $0.5 \mathrm{ml}$ of trichloroacetic acid were added to centrifuge tubes $(100 \mathrm{~g} / \mathrm{L})$, and after that stirred and centrifuged for $30 \mathrm{~min}$ at $3000 \mathrm{rpm}$. The supernatant was collected and transferred to a test tube with $4.5 \mathrm{ml}$ of distilled water. The content of the tube was stirred and measured at $\lambda 254 \mathrm{~nm}$. The quantity of oligopeptides was estimated by the level of proteins in the supernatant by Bradford method.

\section{Ultrasound examination of rats}

We performed the liver and kidney ultrasonography (US) in two rats of each group using linear 5-12 $\mathrm{MHz}$ frequency probes of ultrasound scanner Ultrasound Philips/ATL HDI 3500 (Netherlands).

\section{Statistical analysis}

Statistical analysis was performed by using "Statistica 7.0" software. All experimental data in this study were expressed as means \pm standard deviation $(\mathrm{M} \pm \mathrm{SD})$. Statistical analysis was performed by using one-way analysis of variance (ANOVA). The difference between groups was defined to be statistically significant when a $p$ value was lower than 0.05 .

\section{Results}

The baseline information of body weight, body mass index, and Lee index of experimental animals are presented on the Table 1. The results of the study are presented on Figs. 1, 2, 3, 4,5 , and 6 .

Our results demonstrate significant increasing levels of $\mathrm{MM}$ in the blood of male rats fed with high-calorie diet, indicating the development of EIS (Fig. 1).

Concurrently, significant changes were detected in the oligopeptides fraction (Fig. 2).

The results of current study indicate significant changes in the content of MM by administration of Orlistat and
Fig. 1 Effect of

bionanocomposite and Orlistat on level of middle mass molecules in blood serum. Data are presented as the $\mathrm{M} \pm \mathrm{SD} ; * p<0.05$ compared with control value

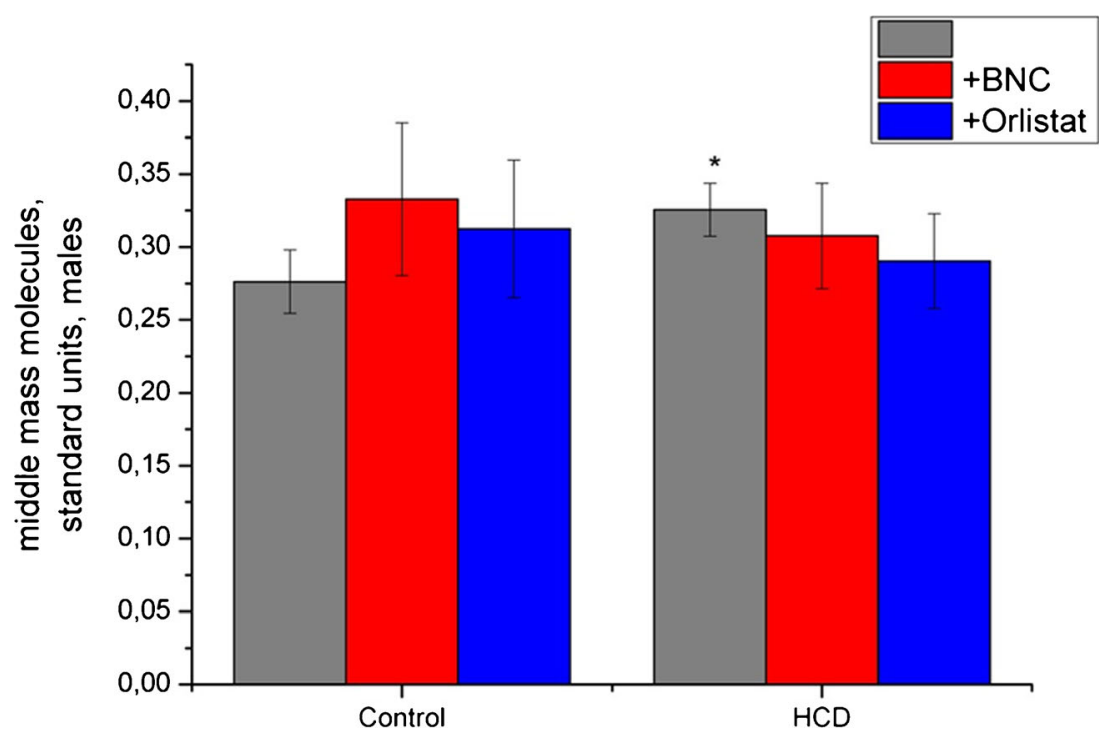


Fig. 2 Effect of

bionanocomposite and Orlistat on level of oligopeptides in blood serum. Data are presented as the $\mathrm{M} \pm \mathrm{SD} ; * p<0.05$ compared with control value, ${ }^{\#} \mathrm{p}<0.05$ compared with $\mathrm{HCD}$ value

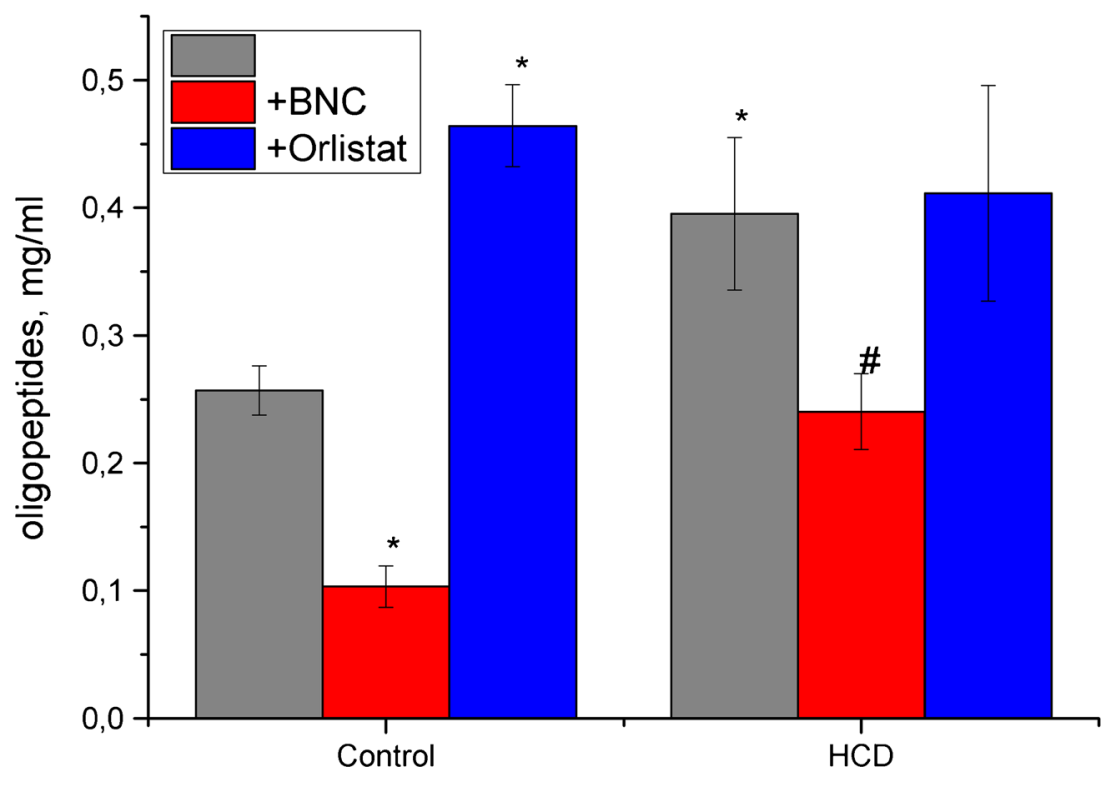

BNC based on Fenugreek: MM levels in serum in rats under high-calorie diet in the application of both compounds were not significantly different from control values. At the same time, significant changes were observed in oligopeptides fraction. Treating by Orlistat not only reduced the level of degradation products of proteins in rats with high-calorie diet but also can induce their large increase in the control group.

Our results indicate a significant increase of all studied serum markers of the kidney function in HCD rats. This indicates the kidney failure development, including the filtration capacity, and confirms our hypothesis that high-calorie diet induces increasing oligopeptide levels in serum and damage of nephron glomeruli.

Similar to effects on serum levels of oligopeptides, Orlistat treatment evokes a high increasing serum creatinine in control animals and did not normalize it in the experimental rats group (Fig. 3). These results and the tendency to increase the levels of urea and uric acid confirm the severe damaging effects of this drug on the ultrafiltration process. Fenugreek-based BNC treatment did not induce kidney failure and changes in the studied marker levels in a control group (Fig. 4).

Concurrently, the results of our research indicate normalization in blood content of uric acid and urea, both under the action of Orlistat and under the use of BNC (Figs. 4 and 5).

We revealed liver enlargement and nephropathy signs including thinning, increasing echogenicity of kidney parenchyma, and increasing resistance index (RI) in renal arteries (over 0.7) in obese rats on ultrasound (Fig. 6).
Fig. 3 Effect of

bionanocomposite and Orlistat on level of creatinine in blood serum. Data are presented as the $\mathrm{M} \pm \mathrm{SD}$; $* p<0.05$ compared with control value

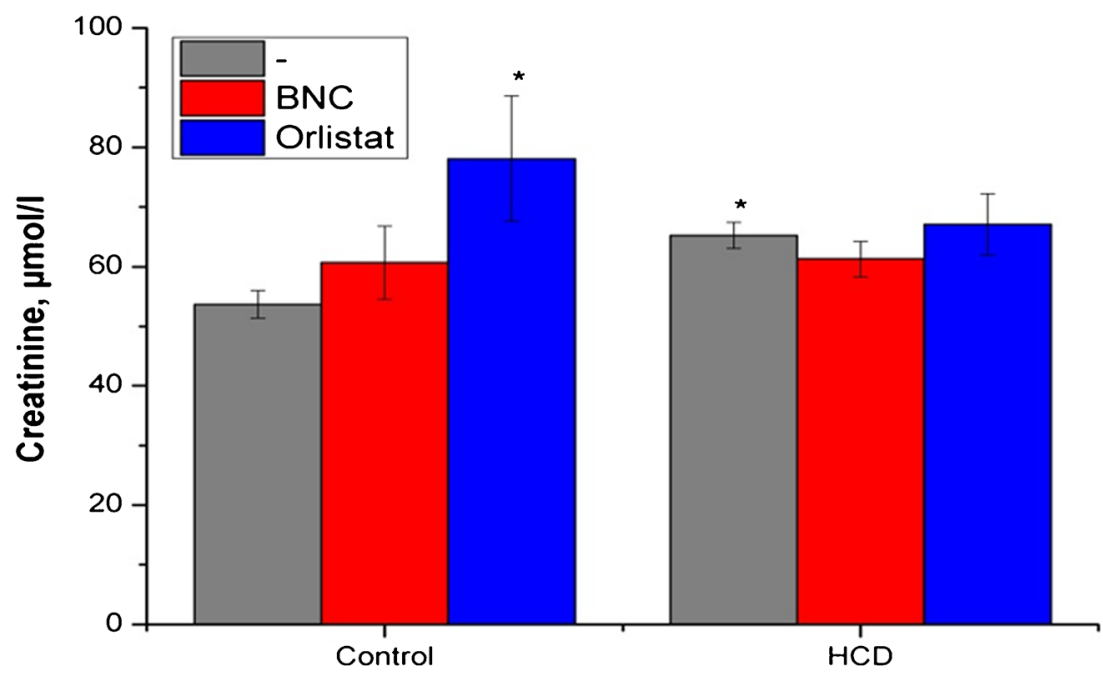


Fig. 4 Effect of

bionanocomposite and Orlistat on level of urea in blood serum. Data are presented as the $\mathrm{M} \pm \mathrm{SD}$; $* p<0.05$ compared with control value, ${ }^{\#} p<0.05$ compared with $\mathrm{HCD}$ value

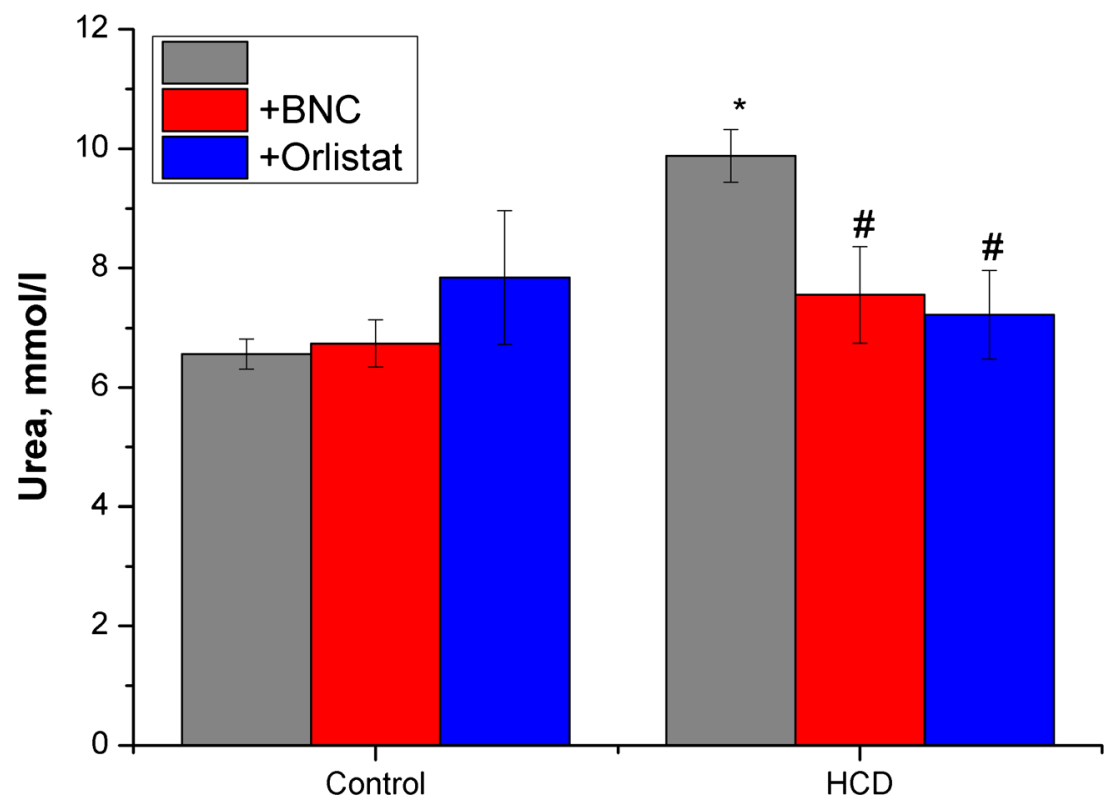

\section{Discussion}

\section{EIS markers in obesity}

The accumulation of oligopeptides can be the result of enhanced activity of proteolytic enzymes [5, 18-20]. Obesity and relative diseases are associated with increasing proteolysis and oxidative stress [21-23]. Activation of free radical oxidation can increase endogenous intoxication and the increasing the MM levels in the blood [23]. However, the mechanism of the enhanced oxidative stress in obesity is currently poorly understood, and evidence on links between uremia-related oxidative stress and MM levels is unclear; recently, it swas reported that $\beta 2$-microglobulin, a traditional MM marker, may not by itself contribute to the pathogenesis of CKD by induction of leukocyte oxidative stress [24]. It was evidenced that oxidative stress is associated with increased expression of genes encoding NADPH oxidase subunits and reduced expression of enzymatic antioxidants genes [25]. Finally, another reason for the increasing of the MM level in obesity condition may be a violation of renal excretory capacity [26-30].

The Orlistat effects on MM levels can be explained by the side effects of this drug like steatorrhea, and inhibition of fat reabsorption in the gut antioxidants like vitamin $\mathrm{A}$ and $\mathrm{E}$ is disturbed [7, 9]. Development of oxidative stress, contributing to modification of proteins, can be involved in increasing their catabolism. Orlistat can decline glomerular filtration that also slows down the oligopeptide excretion $[31,32]$.
Fig. 5 Effect of

bionanocomposite and Orlistat on level of uric acid in blood serum. Data are presented as the $\mathrm{M} \pm \mathrm{SD}$; $* p<0.05$ compared with control value, ${ }^{\#} p<0.05$ compared with $\mathrm{HCD}$ value

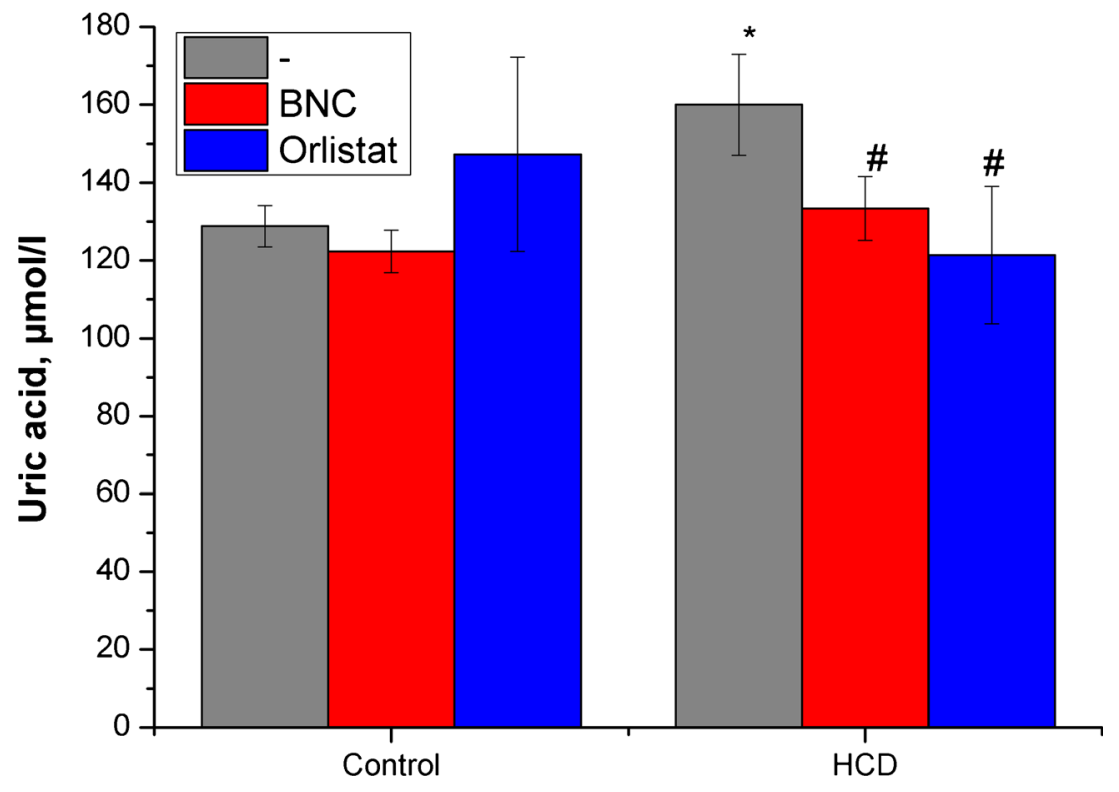


Fig. 6 Ultrasound scan of the kidney in rat using Doppler sonography of renal arteries. $K$ kidney, ellipse RI measured on segmental artery

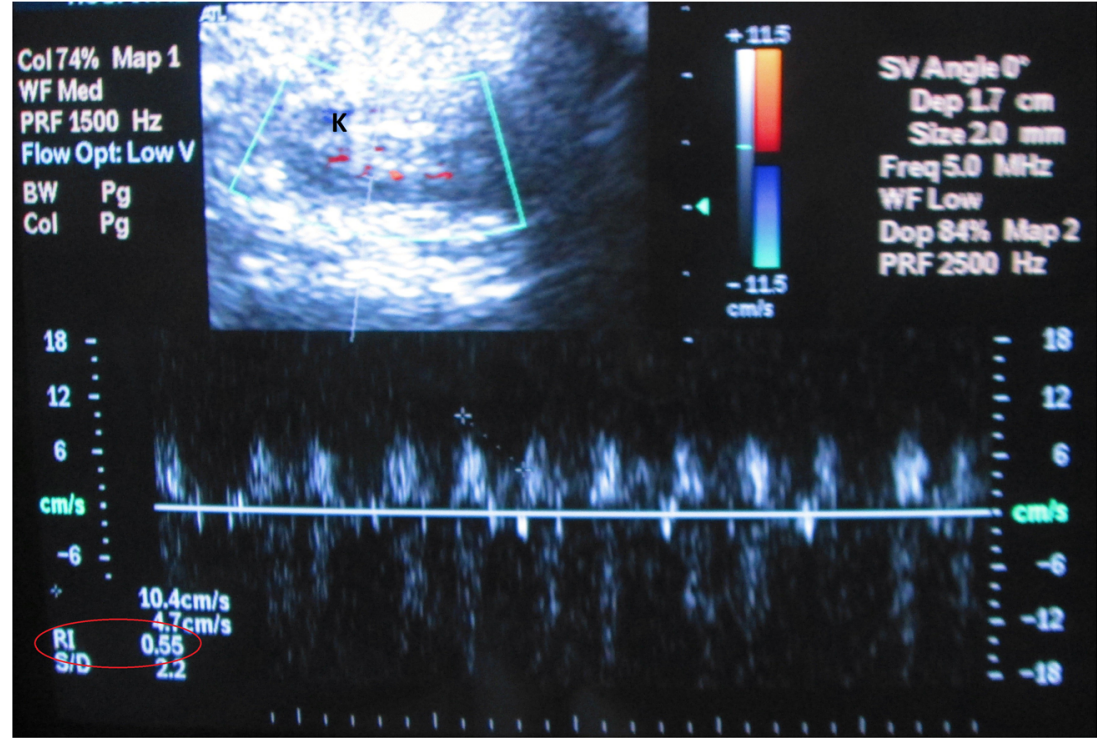

Unlike Orlistat, BNC based on Fenugreek significantly reduces the serum level of oligopeptides both in the control group and in the HCD rats. In the latter case, the value of the parameter did not significantly differ from the norm.

The reduction of EIS peptide markers under Fenugreek$\mathrm{BNC}$ treatment is likely due to the antioxidative properties of polyphenols and bioflavonoids, saponin, vitamins, selenium, etc. present in Fenugreek. Fenugreek includes three main components as follows: diosgenin (the most important saponin of this plant), 4-hydroxyisoleucine (4-OH-Ile), and galactomannans exhibit powerful effects on the glucose and lipids metabolism, insulin signaling system, liver and kidneys' functional states, and the development of inflammatory processes $[10,11,13]$. A number of studies indicate that the Fenugreek components have the ability to scavenge ROS, to inhibit the lipid peroxidation processes, and to promote the enzymatic antioxidants functions [14, 33]. The administration of Fenugreek improves renal function also by significantly decreasing calcification processes in the renal tissue, increasing the level of antioxidant protection, and reducing oxidative stress displays including lipid peroxidation inhibition [34, 35].

\section{Kidney injury markers in obesity}

A number of studies [28-30] have shown that the high-calorie diet alter kidney structure and renal morphometric parameters in rats and induce changes in the kidney weight, total kidney volume, volume of cortex, medulla, glomeruli, proximal and distal tubules, and nephron degeneration including glomerulosclerosis and tubular defects.

In normal physiological conditions in rats, urea is freely filtered at the glomerulus and then is reabsorbed in the inner medullary collecting duct (IMCD) of the kidneys, engaging in the processes of urine concentration $[15,36]$, but certain conditions, e.g., low-protein diet induce expression of genes of the proteins, secondary-active transport of urea is involved.

Detected differences among changes in serum levels of markers of kidney function, most likely, are due to the peculiarities of transport in the nephron, including energydependent reabsorption of urea and urate that involves a number of transport proteins and therefore may be subject to acute and chronic regulation. Some tendencies to increase creatinine levels under Fenugreek-based BNC treatment may occur due to the amount of muscle mass [15] and possible anabolic properties of Fenugreek. It may also explain the absence of reliable changes in creatinine levels when used in HCD rats (the oligopeptides levels at the same time are normalized since their content does not depend on the intensity of anabolic processes in muscle) [37]. Creatinine elimination from the body occurs only in the kidneys by glomerular filtration processes and partly $(10-40 \%)$ via active secretion in the proximal tubules of the nephron, which is mediated by specific transport proteins of basolateral (OAT2, OAT3, OCT2, OCT3) and apical (MATE1 and MATE2-K) membranes [38] (Fig. 7).

The general scheme of the study and action of Orlistat and Fenugreek-based BNC is presented on Fig. 8.

Acute regulation of urea transport is done by their phosphorylation. Chronic regulation involves altering protein abundance in response to changes in hydration status, low protein diets, adrenal steroids, sustained diuresis, or antidiuresis [39-41]. Secondary-active transport of urea in the rat kidneys is inducible and involves three sodiumdependent urea transporters which are involved into active urea reabsorption in the apical and basolateral membrane of initial part of IMCD, and also in active urea secretion in the apical membrane of terminal IMCD [42-44]. 
Fig. 7 The simplified scheme of creatinine, urea, and urate renal transport in rats

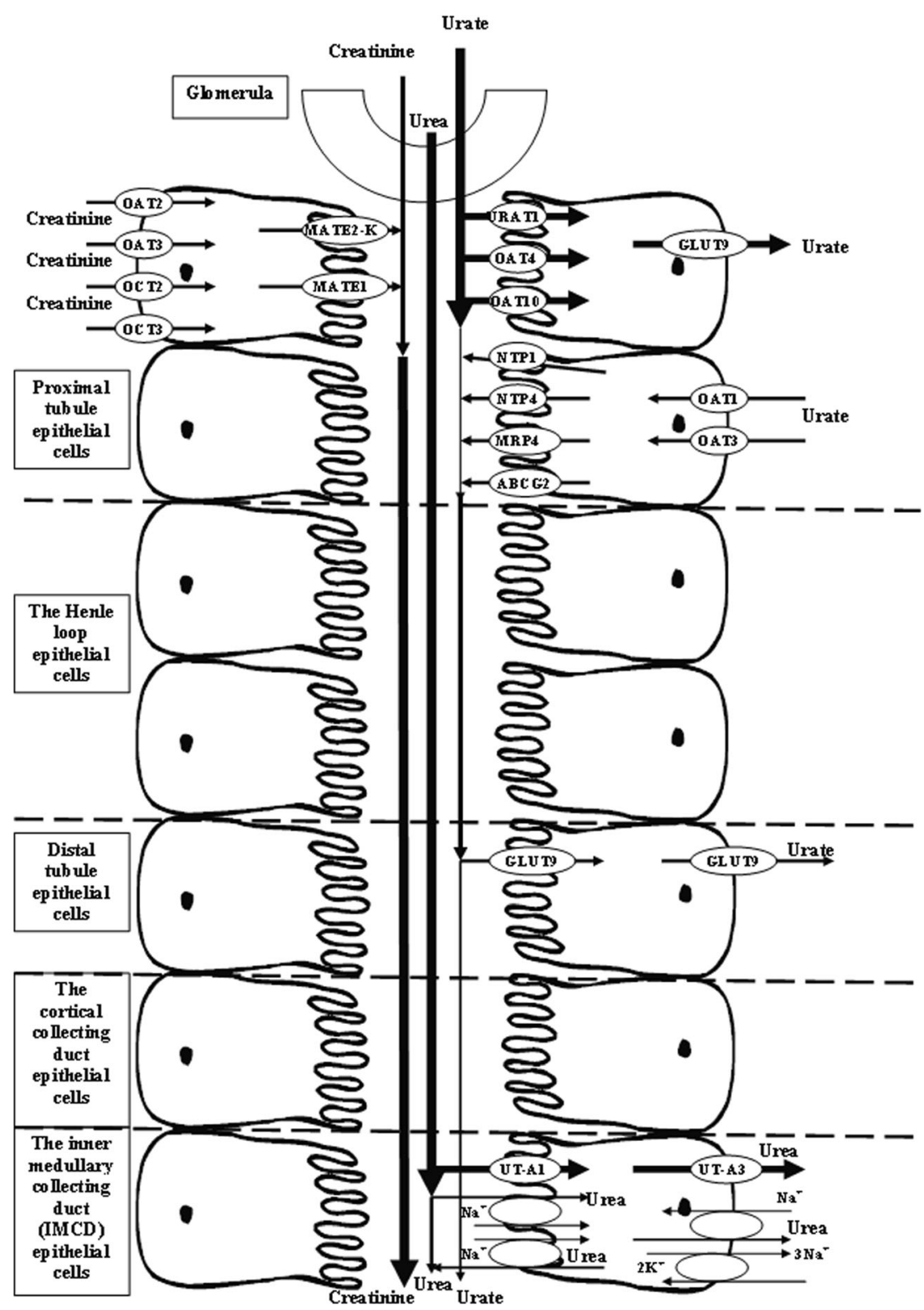

Unlike the human and higher primate organisms, where the levels of creatinine, urea, and uric acid in serum or plasma correlate with the state of ultrafiltration processes in the renal glomeruli, since they are not metabolized and excreted unchanged with the urine, creatinine and urea only can be considered as relevant markers in rats. Rats and most other mammals demonstrate high activity of uricase, the enzyme, which metabolize urate to allantoine and therefore its activity can significantly influence on urate content in the blood $[15,36]$.

About $90 \%$ of filtered urate is reabsorbed in the kidney; transport systems responsible for the reabsorption of urate in the nephron cells are found in both human and rats [36, 45-47]. The most important of them are URAT1 and GLUT9 [45-47]. Disruption of renal regulation of serum urate content is one of the pathological factors of hyperuricemia and gout. The analogous transport system in rats reveals $74 \%$ homology in amino acid sequence and has the same features and location, but a lower affinity for urate [45].

The observed reduction in serum levels of urea and urate under Orlistat treatment in obese rats is associated not only with the normalization of ultrafiltration in the glomeruli of nephron but also with the possible influence on the uricase activity.

Overall, despite the high efficiency of synthetic disaccharidase and lipase inhibitors, to reduce glucose and lipids levels in the blood, the antiobesogenic drugs, particularly Orlistat, have significant side effects that cause serious damage of the kidneys with accumulation of oligopeptides and consequently the development of the EIS.

Considering the above notes, the marker level changes under the BNC based on Fenugreek treatment along with normalization of the kidney glomeruli function may be partially 


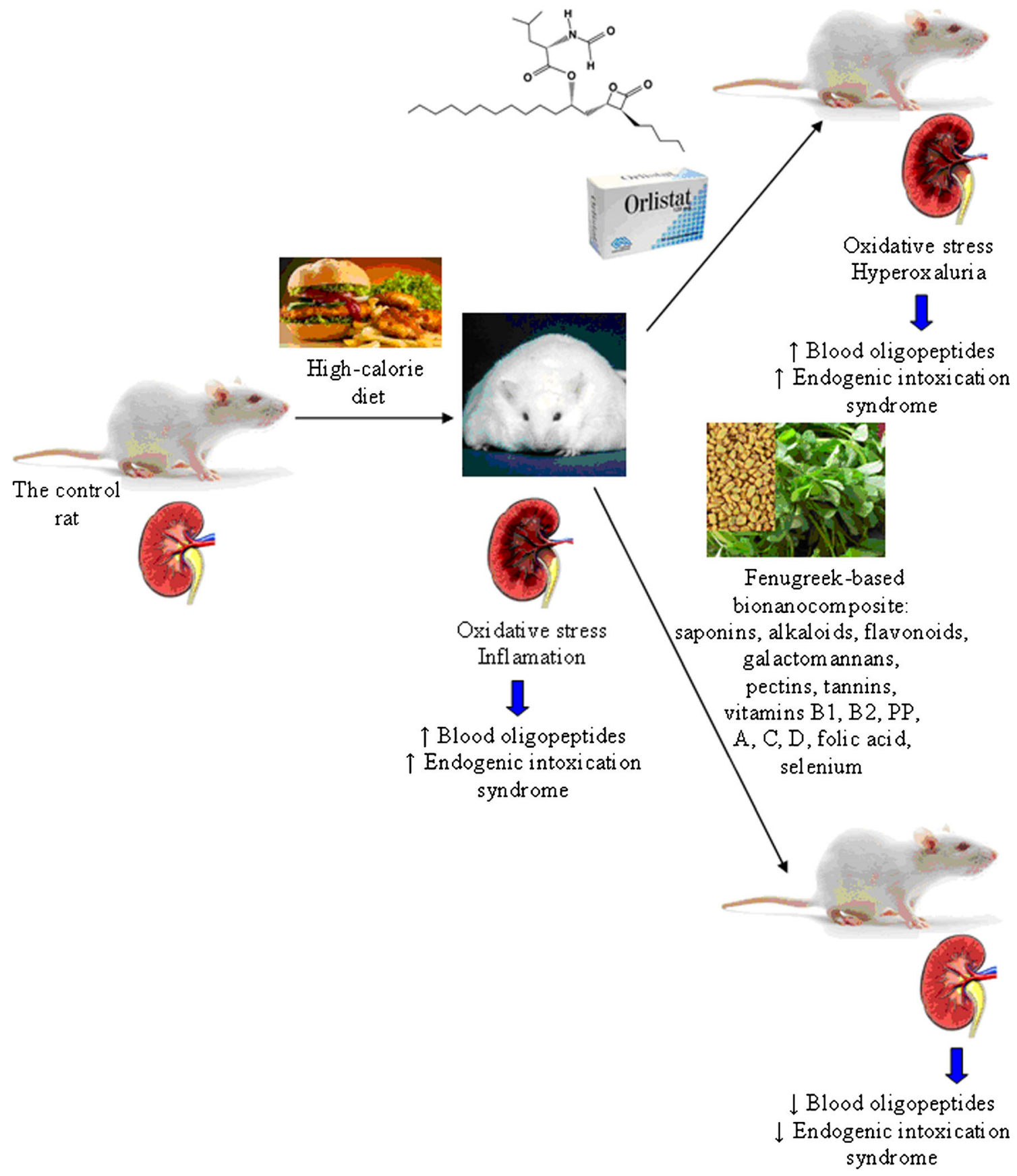

Fig. 8 The general scheme of the study and action of Orlistat and Fenugreek-based bionanocomposite

associated with the same influence of biologically active Fenugreek components on complex mechanisms of reabsorption and secretion of urea and urate in the kidneys.

\section{Reliable obesity animal models}

Obesity models require multifactorial approach according to principle causality factors and reflect development in humans. Various rodent models of chronic kidney diseases have been developed to study pathogenesis and mechanisms to simulate neuroendocrine, nutrition, or genetically induced changes and effects of interventions; animal models of obesity have been developed, including spontaneous, genetic, and induced models. The high-calorie diet model [48] is simple and reliable approach. Recently, we have studied monosodium glutamate-induced obesity and concluded that the introduction of MSG to newborn rats caused the obesity in adulthood [49]. However, these models do not exactly simulate human diseases, recurrent or progressive injuries in glomeruli, tubules, interstitium, and/or vasculature and furthermore, most of them are strain, gender, or age dependent [50]. Rodent models remain the most popular species to approximate 
human disease. There has been a progressive increase in studies using mouse models of renal disease vs the use of rats [28, 50]. Several models addressed to collateral diseases consider cardiovascular parameters in the development renal injury [51-53]. The use of HFD in the C57BL/6 mouse is a suitable model to induce whole body and metabolic effects commonly seen in the human MetS and is associated with renal damage likely to lead to progressive renal disease [54].

\section{T. foenum-graecum, a component of traditional diets, has a potential for prevention and treatment MetS}

The beneficial properties of Fenugreek were reported, such as antidiabetic and galactagogue (lactation-inducer) effects; newer research has identified hypocholesterolemic, carminative, gastric stimulant, antioxidant, antilipidemia, antibacterial, hepatoprotective, antifungal, antiinflammatory, antilithigenic, antiulcer, anticarcinogenic, etc. $[10,11,13$, 14, 54-58].

Fenugreek does not produce any significant acute and cumulative toxicity at the doses administered [55]. According to results by Kumar et al. [56], Fenugreek treatment offered significant protection against dyslipidemia and oxidative stress. Fenugreek demonstrated beneficial effects on blood glucose and insulin levels, antioxidant enzymes, lipid peroxidation, pyruvate kinase, lactate dehydrogenase, and protein kinase $\mathrm{C}$ in the heart, muscle, and brain of the alloxan-induced diabetic rats. Results of the study by Uemura et al. [57] showed that T. foenumgraecum can ameliorate hyperglycemia and diabetes. Authors determined the effects of Fenugreek on adipocyte size and inflammation in adipose tissues in diabetic obese KK-Ay mice, and identified the active substance in Fenugreek. Thus, Fenugreek miniaturized the adipocytes and increased the mRNA expression levels of differentiation-related genes in adipose tissues; Fenugreek also inhibited macrophage infiltration into adipose tissues and decreased the mRNA expression levels of inflammatory genes. Fenugreek, which contains diosgenin, may be useful for the management of diabetes-related hepatic dyslipidemias. Fenugreek might offer effective added advantages as prebiotic towards the enhancement of probiotic bacterial growth in the gastrointestinal environment [58] and is promising for development treatments on immune-related disorder [59].

In our study, the use of BNC based on Fenugreek reduces the oligopeptides level in control group rats, and normalizes in experimental group likely due to presence of active antioxidant ingredients in Fenugreek: diosgenin, galactomannans, vitamins-antioxidants, selenium, etc., along with the normalization of the lipids and carbohydrates metabolism, improve function of organ that provides release of endogenous toxins that belong to the oligopeptides group (proved by decreasing of urea and serum urate levels).

\section{MetS, hyperuricemia, and nephropathy}

Hyperuricemia, which is strongly associated with obesity and MetS and nephropathy can predict visceral obesity and insulin resistance, might be partially responsible for the pro-inflammatory endocrine imbalance in the adipose tissue, which is an underlying mechanism of the lowgrade inflammation and insulin resistance in subjects with the MetS [60-65]. Gout is a common metabolic disorder, involving the liver, kidney, and joints; it is met more often in men, and is characterized by the deposition of reversible monosodium urate (MSU) crystals and occurs as a consequence of hyperuricemia which induces inflammatory arthritis and nephropathy. Serum uric acid levels are elevated in secondary insulin resistance syndromes (e.g., gout, transplantation, pre-eclampsia, and diuretic use [45-47, 65].

In the study by Köttgen et al. [28], genome-wide significant loci associated with serum urate concentrations were identified. Those alleles associated with increased serum urate concentrations can increase the risk of gout. The modulation of urate production and excretion by signaling processes that influence metabolic pathways, such as glycolysis and the pentose phosphate, seem to be central pathways including the genes from the newly identified associated loci. These findings may have implications for further research into urate concentration, lowering drugs to treat and prevent the common inflammatory arthritis and gout [66].

Uric acid predicts, and is an integral component and causal factor in the hypertension [67]; uric acid-induced endothelial dysfunction with impaired NO production might mediate development of insulin resistance and hypertension.

Evidence is growing, supporting involvement of uric acid in development of insulin resistance. Experimental hyperuricemia induces diabetes and hypertension in animals, while fructose intake may have a major role in the epidemic of MetS and obesity due to its ability to raise uric acid. Fructose ingestion increases serum uric acid and leads to hypertension, insulin resistance, obesity, and hypertriglyceridemia; these conditions are ameliorated by decreasing uric acid levels [68, 69].

Advanced imaging modalities including magnetic resonance imaging (MRI), ultrasound (US), computed tomography (CT), and dual energy CT have important applications in gout and can capture information about the composite, vascular nature of many tophaceous deposits [70-72].

More studies are required to establish the links with food additives (e.g., glutamate) and crystal deposition diseases, prior to the gout [49]. 


\section{Conclusions}

Increase in the content of MM and oligopeptides in the blood of rats with experimental obesity was demonstrated, which may be the result of both intensive proteolysis, including oxidation-modified proteins, and strong elevation of kidney function marker contents in the blood. The application of Orlistat and Fenugreek-based BNC decreases the levels of $\mathrm{MM}$ to the normal range. Concurrently, the use of Orlistat is associated with increasing levels of oligopeptides in both control group and in rats under HCD, likely due to severe side effects on kidneys via pro-oxidant actions.

\section{Outlooks and recommendations}

\section{Consolidation of the PPPM concept}

Obesity and metabolic syndrome have been profoundly studied by experts of European Association for Predictive, Preventive and Personalised Medicine (EPMA) and remain the focus of frontier research [73-76]. Current paper is the follow-up of the previous works by the group [4, 17, 48, 49, $51,59,72]$, and it arises many essential multidisciplinary issues for obesity complications, and related conditions to be adopted in clinical set to yield safer, more effective, and expensive medical interventions with higher value [76]. These results provide a basis for more in-depth studies of the Fenugreek effects potential for the prevention and treatment of obesity-related diseases and managing patients with CKD holistically.

\section{Predictive medical approach}

Translation of obtained results to human organism is quite a challenge for developing the integral obesity, and renal panel of imaging and molecular biomarkers is an important point. Considering involving vascular dysfunction, mediated by endothelial nitric oxide and signaling during obesity and vascular regulation in renal dysfunction, the risk of development of cardiovascular and metabolic diseases dramatically increases. Endothelial dysfunction induced by obesity and concept of Flammer syndrome might have considered as an important risk factor including for stratification patients with MetS and kidney disease $[77,78]$.

\section{Preventive medical approach}

This study supports the evidence on the role of high calorie diet to obesity complications [79] in particular for renal dysfunction providing reliable causality evidence.

Lifestyle modification programs include effective nonpharmacological approaches, like physical therapy, use of probiotics, and personalized diets. Available evidence shows that increasing, or even starting, regular physical exercise improves insulin sensitivity, thereby reducing cardiovascular risk and influencing CKD outcomes [1].

Obesity prevention via designing person-related diet corrections is a principle message on preventive measures against obesity epidemic. Although, raising awareness levels and developing accurate screening methods may allow more timely diagnosis and relevant programs [80]. Translation of the currently obtained data on animal model to human organism should allow to consider dietary impacts on obesity, insulin resistance, and renal function, and develop personalized diets [81]. Delivering effective nutritional advice in patients with chronic kidney disease coordinates multiple diet components including calories, protein, sodium, potassium, calcium, phosphorus, and fluid. However, studies have shown difficulty in adhering to the scope and complexity of the diet parameters; no single educational or clinical strategy was considered effective so far [82].

Fenugreek can be considered a potentially effective prebiotic for a number of beneficial applications and advances in development of treatments of immune-related disorders [58, 59]. Dysbiosis of the gut microbiota is involved in severe conditions such as chronic kidney disease but whether the gut-microbiome link is altered in hypertension has not been elucidated [83].

Obesity treatments utilizing pharmacology approaches should be carefully reconsidered due to their side effects in particular on renal function.

Strong potential is in the prevention of hyperuricemia; more studies are required to establish the links with food additives (e.g., glutamate) urate metabolism and crystal deposition diseases, prior to gout [49].

\section{Personalized medical approach}

On our best knowledge, this is the first study on efficacy of Fenugreek-based drug for the kidney disease in obesity. Due to the safety of Fenugreek consisting components, it is easy to translate and set human research soon. The results of the study are potentially applicable to create products, drugs, and food supplements for treatment and to develop safe and effective treatments beneficial for individual outcomes. Hybrid techniques with regenerative and nanomedicine are very interesting and promising applications, in particular using nanoparticles capable of reducing the level of oxidative stress against metabolic syndrome and during aging [84]. Repair/regenerative capacity of using stem cell-based therapies, recently demonstrating high level of efficacy and safety [85], could improve the outcomes in patients with CKD [86]. 


\section{Limitations of the study}

We are aware of several limitations of our research. The main limitation is that the study has been done on animals. We included only male rats. Using mouse vs rat model can be also debatable for this kind of research, since mouse model might be more reliable for some parameters (e.g., microbiome). We did not include patomorphology data to current paper using in vivo longitudinal renal biopsies under guidance. We considered but not studied at current stage the issues like extensive metabonomics approach; inflammatory and cytokine signaling pathways; apoptosis; plasmin, matrix metalloproteinases, and proteolytic enzymes of leukocytes and lysosomes; regenerative potential and stem cell status; microbiome; uric acid metabolites; and genetics. A multifactorial origin of MetS and renal dysfunction, like cardiovascular issues, has not been also put into research at this stage.

Acknowledgements Seeds of Trigonella foenum-graecum L. varieties Ovari were provided by Professor of the University of West Hungary Sándor Makai (Institute of Crop Sciences, Department of Medicinal and Aromatic Plants). The study was conducted with the support of the State Agency on Science, Innovations, and Informatization of Ukraine. We acknowledge the EPMA Journal editorial team for the opportunity to publish this work.

Authors' contributions VVK and TVI performed experiments and analysis of the study, did the literature review in part of the discussion, and formulated prospects. LIO suggested the idea of the study and did the organization. TBS prepared the first draft of manuscript, did the literature analysis, and reviewed the case studies. IIG involved in the collection of literature, interpreted the results, and performed the statistical analysis. MYS did the revision manuscript and new data interpretation and did the contribution to the overall development of the studied topic. RVB did the ultrasound survey, study analysis, work on the second manuscript draft, prepared discussion, formulated future outlooks and the PPPM concept, and performed second and final article drafting. All authors read and approved the final manuscript.

Compliance with ethical standards Research was conducted in compliance with the standards of the Convention on Bioethics of the Council of Europe's "Europe Convention for the Protection of Vertebrate Animals" used for experimental and other scientific purposes (1997), and with other international agreements and national legislation in this field.

Ethics approval and consent to participate Not applicable.

Consent for publication Not applicable.

Availability of data and material Not applicable.

Competing interests The authors declare that they have no competing interests.

Funding Not applicable.

Authors' information VVK, Ph.D.; IIG, Ph.D.; TVI, Ph.D.; and TBS, $\mathrm{Ph} . \mathrm{D}$. are researchers at Educational and Scientific Centre "Institute of
Biology," Taras Shevchenko National University of Kyiv. Professor LIO, D.Sci. is a director of Educational and Scientific Centre Institute of Biology, Taras Shevchenko National University of Kyiv. Professor MYS, Ph.D., D.Sci. is a corresponding member of the National Academy of Sciences of Ukraine and the director of the Interferon Department of Zabolotny Institute of Microbiology and Virology, NAS of Ukraine. RVB, M.D., Ph.D. is a researcher of the Inteferon Department of Zabolotny Institute of Microbiology and Virology, National Academy of Sciences of Ukraine and a medical doctor in the Clinical Hospital "Pheophania" of the State Affairs Department and National Representative of the European Association for Predictive, Preventive, and Personalised Medicine (EPMA) in Ukraine.

\section{References}

1. Câmara NO, Iseki K, Kramer H, Liu ZH, Sharma K. Kidney disease and obesity: epidemiology, mechanisms and treatment. Nat Rev Nephrol. 2017;13(3):181-90. doi:10.1038/nrneph.2016.191.

2. Schlondorff DO. Overview of factors contributing to the pathophysiology of progressive renal disease. Kidney Int. 2008;74: $860-6$.

3. Chornenka NM, Raetska YB, Savchuk OM, Kompanets IV, Beregova TV, Ostapchenko LI. Effect of different doses of melanin in the blood protein changes in rats under alkaline esophageal burns. Res J Pharm, Biol Chem Sci. 2016;7(5):1042-7. http:// www.rjpbcs.com/pdf/2017_8(1)/[34].pdf. Accessed 1 May 2017

4. Vanholder R, De Smet R, Glorieux G, Argilés A, Baurmeister U, Brunet $P$, et al. Review on uremic toxins: classification, concentration, and interindividual variability. European Uremic Toxin Work Group (EUTox). Kidney Int. 2003;63(5):1934 43.

5. Babb AL, Ahmad S, Bergström J, Scribner BH. The middle molecule hypothesis in perspective. Am J Kidney Dis. 1981;1(1):46-50.

6. Vanholder R, Van Laecke S, Glorieux G. The middle-molecule hypothesis 30 years after: lost and rediscovered in the universe of uremic toxicity? J Nephrol. 2008;21(2):146-60.

7. Guerciolini R. Mode of action of. Int J Obes Relat Metab Disord. 1997;21(Suppl 3):S12-23.

8. García Díaz E, Martín Folgueras T. Systematic review of the clinical efficacy of sibutramine and orlistat in weight loss, quality of life and its adverse effects in obese adolescents. Nutr Hosp. 2011;26(3): 451-7.

9. Karimi G, Sabran MR, Jamaluddin R, Parvaneh K, Mohtarrudin N, Ahmad Z, et al. The anti-obesity effects of Lactobacillus casei strain Shirota versus Orlistat on high fat diet-induced obese rats. Food Nutr Res. 2015;59:29273. doi:10.3402/fnr.v59.29273.

10. Kumar P, Bhandari U. Common medicinal plants with antiobesity potential: a special emphasis on fenugreek. Anc Sci Life. 2015;35: 58.

11. Akbari M, Rasouli H, Bahdor T. Physiological and pharmaceutical effect of fenugreek: a review. IOSR J Pharm. 2012;2:49.

12. Geetha M, Reddy S, Krupanidhi A. Effect of fenugreek on total body and organ weights: a study on mice. Pharmacologyonline 2011, 3: 747-752. http://pharmacologyonline.silae.it/files/ newsletter/2011/vol3/073.patil.pdf Accessed 1 May 2017.

13. Fuller S, Stephens J. Diosgenin, 4-hydroxyisoleucine, and fiber from fenugreek: mechanisms of actions and potential effects on metabolic syndrome. Adv Nutr. 2015;6:189.

14. Jiang W, Gao L, Li P, Kan H, Qu J, Men L, et al. Metabonomics study of the therapeutic mechanism of fenugreek galactomannan on diabetic hyperglycemia in rats, by ultra-performance liquid chromatography coupled with quadrupole time-of-flight mass spectrometry. J Chromatogr B Analyt Technol Biomed Life Sci. 2017;10441045:8-16. doi:10.1016/j.jchromb.2016.12.039. 
15. Gowda S, Desai P, Kulkarni S. Markers of renal function tests. N Am J Med Sci. 2010;2:170-3.

16. Shen H, Tang Q, Huang J. Vitamin E regulates adipocytokine expression in a rat model of dietary-induced obesity. Exp Biol Med. 2010;235:47-51.

17. Konopelnyuk VV, Goloborodko II, Tymoshenko MO, Ostapchenko LI. Bionanocomposite prevents body weight gain in high calorie diet —obese rats. IJHSR. 2016;6(4):354-61. http:// www.ijhsr.org/IJHSR_Vol.6_Issue.4_April2016/49.pdf Accessed 1 May 2017

18. Hua Y, Nair S. Proteases in cardiometabolic diseases: pathophysiology, molecular mechanisms and clinical applications. Biochim Biophys Acta. 2015;1852(2):195-208. doi:10.1016/j.bbadis.2014. 04.032 .

19. Van Hul M, Lijnen R. A functional role of gelatinase a in the development of nutritionally induced obesity in mice. J Thromb Haemost. 2008;6(7):1198-206. doi:10.1111/j.1538-7836.2008. 02988.x.

20. Van Hul M, Lijnen H. Matrix metalloproteinase inhibition affects adipose tissue mass in obese mice. Clin Exp Pharmacol Physiol. 2012;39:544.

21. Jensen M, Haymond M. Protein metabolism in obesity: effects of body fat distribution and hyperinsulinemia on leucine turnover. Am J Clin Nutr. 1991;53:172.

22. Noeman SA, Hamooda HE, Baalash AA. Biochemical study of oxidative stress markers in the liver, kidney and heart of high fat diet induced obesity in rats. Diabetol Metab Syndr. 2011;3(1):17. doi:10.1186/1758-5996-3-17.

23. Roumelioti ME, Nolin T, Unruh ML, Argyropoulos C. Revisiting the middle molecule hypothesis of uremic toxicity: a systematic review of beta 2 microglobulin population kinetics and large scale modeling of hemodialysis trials in silico. PLoS One. 2016;11(4): e0153157. doi:10.1371/journal.pone.0153157.

24. Neirynck N, Glorieux G, Boelaert J, Schepers E, Liabeuf S, Dhondt A, et al. Uremia-related oxidative stress in leukocytes is not triggered by $\beta 2$-microglobulin. J Ren Nutr. 2013;23(6):456-63. doi: 10.1053/j.jrn.2013.07.002.

25. Kalivarathan J, Chandrasekaran SP, Kalaivanan K, Ramachandran V, Carani VA. Apigenin attenuates hippocampal oxidative events, inflammation and pathological alterations in rats fed high fat, fructose diet. Biomed Pharmacother. 2017;89:323-31. doi:10.1016/j. biopha.2017.01.162.

26. Leypoldt JK, Holmes CJ, Rutherford P. Clearance of middle molecules during haemodialysis and haemodiafiltration: new insights. Nephrol Dial Transplant. 2012;27:4245-7.

27. Maduell F, Arias-Guillen M, Fontseré N, Ojeda R, Rico N, Vera M, et al. Elimination of large uremic toxins by a dialyzer specifically designed for high-volume convective therapies. Blood Purif. 2014;37(2):125-30. doi:10.1159/000358214.

28. Wicks S, Nguyen T, Breaux C. Diet-induced obesity and kidney disease - in search of a susceptible mouse model. Biochimie. 2016;124:65.

29. Wickman C, Kramer H. Obesity and kidney disease: potential mechanisms. Semin Nephrol. 2013;33:14.

30. Altunkaynak M, Özbek E, Altunkaynak B. The effects of high-fat diet on the renal structure and morphometric parametric of kidneys in rats. J Anat. 2008;212:845. doi:10.1111/j.1469-7580.2008. 00902.x.

31. Beyea M, Garg A, Weir M. Does orlistat cause acute kidney injury? Ther Adv Drug Saf. 2012;3:53.

32. Al-Suwailem A, Al-Tamimi A, Al-Omar M, Al-Suhibani M. Safety and mechanism of action of orlistat (tetrahydrolipstatin) as the first local antiobesity drug. J Appl Sci Res. 2006;2(4):205-8. http:// repository.ksu.edu.sa/jspui/handle/123456789/2280 Accessed 1 May 2017
33. Wani S, Kumar P. Fenugreek: a review on its nutraceutical properties and utilization in various food products. J Saudi Soc Agric Sci. 2017. doi:10.1016/j.jssas.2016.01.007.

34. Laroubi A, Touhami M, Farouk L. Prophylaxis effect of Trigonella foenum graecum $\mathrm{L}$. seeds on renal stone formation in rats. Phytother Res. 2007;21(10):921-5.

35. Anuradha C, Ravikumar P. Restoration on tissue antioxidants by fenugreek seeds (Trigonella Foenum Graecum) in alloxan-diabetic rats. Indian J Physiol Pharmacol. 2001;45:408.

36. Bobulescu I, Moe O. Renal transport of uric acid: evolving concepts and uncertainties. Adv Chronic Kidney Dis. 2012;19:358.

37. Poole C, Bushey B, Foster C, Campbell B, Willoughby D, Kreider $\mathrm{R}$, et al. The effects of a commercially available botanical supplement on strength, body composition, power output, and hormonal profiles in resistance-trained males. J Int Soc Sports Nutr. 2010;7: 34. doi:10.1186/1550-2783-7-34.

38. Lepist E, Zhang X, Hao J. Contribution of the organic anion transporter OAT2 to the renal active tubular secretion of creatinine and mechanism for serum creatinine elevations caused by cobicistat. Kidney Int. 2014;86:350.

39. Promeneur D, Rousselet G, Bankir L. Evidence for distinct vascular and tubular urea transporters in the pat kidney. J Am Soc Nephrol. 1996;7:852.

40. Klein J, Blount M, Sands J. Urea transport in the kidney. Compr Physiol. 2011;1(2):699-729. doi:10.1002/cphy.c100030.

41. Fenton R, Knepper M. Urea and renal function in the 21st century: insights from knockout mice. J Am Soc Nephrol. 2007;18:679.

42. Sands J. Regulation of renal urea transporters. J Am Soc Nephrol. 1999;10:635.

43. Sands J, Martial S, Isozaki T. Active urea transport in the rat inner medullary collecting duct: functional characterization and initial expression cloning. Kidney Int. 1996;49:1611.

44. Kato A, Sands J. Active sodium-urea counter-transport is inducible in the basolateral membrane of rat renal initial inner medullary collecting ducts. J Clin Invest. 1998;102(5):1008-15.

45. Sato M, Wakayama T, Mamada H. Identification and functional characterization of uric acid transporter Urat1 (Slc22a12) in rats. Biochim Biophys Acta Biomembr. 2011;1808:1441.

46. So A, Thorens B. Uric acid transport and disease. J Clin Invest. 2010;120:1791.

47. Hyndman D, Liu S, Miner J. Urate handling in the human body. Curr Rheumatol Rep. 2016;18:34.

48. Karpovets TP, Konopelnyuk VV, Galenova TI, Savchuk AN, Ostapchenko LI. High-calorie diet as a factor of prediabetes development in rats. Bull Exp Biol Med. 2014;156(5):639-41. doi:10. 1007/s10517-014-2414-3.

49. Savcheniuk O, Virchenko O, Falalyeyeva T, Beregova T, Babenko $\mathrm{L}$, Lazarenko L, et al. The efficacy of probiotics for monosodium glutamate-induced obesity: dietology concerns and opportunities for prevention. EPMA J. 2014;5(1):2. doi:10.1186/1878-5085-5-2.

50. Yang H-C, Zuo Y, Fogo AB. Models of chronic kidney disease. Drug Discov Today Dis Models. 2010;7(1-2):13-9. doi:10.1016/j. ddmod.2010.08.002.

51. Spivak M, Bubnov R, Yemets I, Lazarenko L, Timoshok N, Vorobieva A, et al. Doxorubicin dose for congestive heart failure modeling and the use of general ultrasound equipment for evaluation in rats. Longitudinal in vivo study. Med Ultrason. 15(1):23-8.

52. Mullins LJ, Conway BR, Menzies RI, Denby L, John J. Mullins renal disease pathophysiology and treatment: contributions from the rat. Dis Model Mech. 2016;9:1419-33. doi:10.1242/dmm. 027276 .

53. Becker GJ, Hewitson TD. Animal models of chronic kidney disease: useful but not perfect. Nephrol Dial Transplant. 2013;28(10): 2432-8. doi:10.1093/ndt/gft071. 
54. Kontum M. A traditional way of rice preparation with particular benefits for arthritis and musculo-skeletal disorders. J Ayurveda Integr Med. 2010;1(4):241-2. doi:10.4103/0975-9476.74421.

55. Muralidhara, Narasimhamurthy K, Viswanatha S, Ramesh BS. Acute and subchronic toxicity assessment of debitterized fenugreek powder in the mouse and rat. Food Chem Toxicol. 1999;37(8):8318.

56. Kumar P, Taha AKale RK, McLean P, Baquer NZ. Beneficial effects of Trigonella foenum graecum and sodium orthovanadate on metabolic parameters in experimental diabetes. Cell Biochem Funct. 2012;30(6):464-73. doi:10.1002/cbf.2819.

57. Uemura T, Hirai S, Mizoguchi N, Goto T, Lee JY, Taketani K, et al. Diosgenin present in fenugreek improves glucose metabolism by promoting adipocyte differentiation and inhibiting inflammation in adipose tissues. Mol Nutr Food Res. 2010;54(11):1596-608. doi: 10.1002/mnfr.200900609.

58. Haghshenas B, Abdullah N, Nami Y, Radiah D, Rosli R, Yari KA. Microencapsulation of probiotic bacteria Lactobacillus plantarum $15 \mathrm{HN}$ using alginate-psyllium-fenugreek polymeric blends. J Appl Microbiol. 2015;118(4):1048-57.

59. Bubnov RV, Spivak MY, Lazarenko LM, Bomba A, Boyko NV. Probiotics and immunity: provisional role for personalized diets and disease prevention. EPMA J. 2015;6:14.

60. Baldwin W, McRae S, Marek G, Wymer D, Pannu V, Baylis C, et al. Hyperuricemia as a mediator of the proinflammatory endocrine imbalance in the adipose tissue in a murine model of the metabolic syndrome. Diabetes. 2011;60:1258-69. doi:10.2337/ db10-0916.

61. Li C, Hsieh MC, Chang SJ. Metabolic syndrome, diabetes, and hyperuricemia. Curr Opin Rheumatol. 2013;25(2):210-6.

62. Zhu Y, Pandya BJ, Choi HK. Prevalence of gout and hyperuricemia in the US general population. Arthritis Rheum. 2011;63:3136-41. doi:10.1002/art.30520.

63. Mohandas R, Johnson RJ. Uric acid levels increase risk for newonset kidney disease. J Am Soc Nephrol. 2008;19(12):2251-3. doi: 10.1681/ASN.2008091012.

64. Meng XM, Nikolic-Paterson DJ, Lan HY. Inflammatory processes in renal fibrosis. Nat Rev Nephrol. 2014;10(9):493-503.

65. Berkowitz D. Gout, hyperlipidemia, and diabetes interrelationships. JAMA. 1966;197:117-20.

66. Köttgen A, Albrecht E, Teumer A, Vitart V, Krumsiek J, Hundertmark C, et al. Genome-wide association analyses identify 18 new loci associated with serum urate concentrations. Nat Genet. 2013;45(2):145-54. doi:10.1038/ng.2500.

67. Johnson RJ, Feig DI, Herrera-Acosta J, Kang DH. The resurrection of uric acid as a causal factor in hypertension. Hypertension. 2005;45(1):18-20

68. Nakagawa T, Hu H, Zharikov S, Tuttle KR, Short RA, Glushakova $\mathrm{O}$, et al. A causal role for uric acid in fructose-induced metabolic syndrome. Am J Physiol Renal Physiol. 2006;290(3):F625-31.

69. Nakagawa T, Tuttle KR, Short RA, et al. Hypothesis: fructoseinduced hyperuricemia as a causal mechanism for the epidemic of the metabolic syndrome. Nat Clin Pract Nephrol. 2005;1:80-6.

70. McQueen FM, Reeves Q, Dalbeth N. New insights into an old disease: advanced imaging in the diagnosis and management of gout. Postgrad Med J. 2013;89(1048):87-93. doi:10.1136/ postgradmedj-2012-131000.
71. Thiele RG. Role of ultrasound and other advanced imaging in the diagnosis and management of gout. Curr Rheumatol Rep. 2011;13(2):146-53. doi:10.1007/s11926-010-0156-4.

72. Bubnov RV, Melnyk IM. Evaluation of biomarkers for diagnostic decision making in patients with gout using novel mathematical model. Complex PPPM approach. EPMA J. 2014;5(Suppl 1): A58. doi:10.1186/1878-5085-5-S1-A58.

73. Golubnitschaja O, Costigliola V, EPMA. General report \& recommendations in predictive, preventive and personalised medicine 2012: white paper of the European Association for Predictive, Preventive and Personalised Medicine. EPMA J. 2012;3(1):14.

74. Abraham J-A, Golubnitschaja O, Akhmetov I, Andrews RJ, Quintana L, et al. EPMA-World Congress 2015. EPMA J. 2016;7(Suppl 1):9.

75. Golubnitschaja O, Baban B, Boniolo G, Wang W, Bubnov R, Kapalla M, et al. Medicine in the early twenty-first century: paradigm and anticipation-EPMA position paper. EPMA J. 2016;7: 23. doi:10.1186/s13167-016-0072-4.

76. Akhmetov I, Bubnov RV. Innovative payer engagement strategies: will the convergence lead to better value creation in personalized medicine? EPMA J. 2017;8:1. doi:10.1007/s13167-017-0078-6.

77. Toda N, Okamura T. Obesity impairs vasodilatation and blood flow increase mediated by endothelial nitric oxide: an overview. J Clin Pharmacol. 2013;53(12):1228-39. doi:10.1002/jcph.179. doi:10. 1002/jcph.179.

78. Bubnov R, Polivka J Jr, Zubor P, Koniczka K, Golubnitschaja O. Pre-metastatic niches in breast cancer: are they created by or prior to the tumour onset? "Flammer syndrome" relevance to address the question. EPMA J. 2017; doi:10.1007/s13167-017-0092-8.

79. Gabbay E, Slotki I, Shavit L. Weighing the evidence: obesity, metabolic syndrome, and the risk of chronic kidney disease. BMC Nephrol. 2015;16:133. doi:10.1186/s12882-015-0137-y.

80. Chen T, Harris DC. Challenges of chronic kidney disease prevention. Med J Aust. 2015;203:209-10.

81. Zeevi D, Korem T, Zmora N, Israeli D, Rothschild D, Weinberger A, et al. Personalized nutrition by prediction of glycemic responses. Cell. 2015;163:1079-94.

82. Beto JA, Schury KA, Bansal VK. Strategies to promote adherence to nutritional advice in patients with chronic kidney disease: a narrative review and commentary. Int J Nephrol Renovasc Dis. 2016;9: 21-33. doi:10.2147/IJNRD.S76831.

83. Aguilar A. Hypertension: microbiota under pressure. Nat Rev Nephrol. 2017;13(1):3. doi:10.1038/nrneph.2016.173.

84. Zholobak NM, Sherbakov AB, Babenko LS, Bogorad-Kobelska OS, Bubnov RV, Spivak MY, et al. The perspectives of biomedical application of the nanoceria. EPMA J. 2014;5(Suppl 1):A136.

85. Centeno CJ, Al-Sayegh H, Freeman MD, Smith J, Centeno CJ, AlSayegh H, et al. A multi-center analysis of adverse events among two thousand, three hundred and seventy two adult patients undergoing adult autologous stem cell therapy for orthopaedic conditions. Int Orthop. 2016;40:1755-65. doi:10.1007/s00264-0163162-y.

86. Baban B, Liu JY, Payne S, Abebe W, Yu JC, Mozaffari MS. Status of stem cells in diabetic nephropathy: predictive and preventive potentials. EPMA J. 2016;7:21. 